\title{
Self seed production by farmers protect their rights and enhance their sovereignty
}

\author{
Ujjawal Kumar Singh Kushwaha \\ National Plant Breeding and Genetics Research Center, Khumaltar, Lalitpur, Nepal \\ Corresponding email: kushujjwal@gmail.com
}

\begin{abstract}
Farmer's right and their sovereignty is an important issue related with intellectual property rights and agrobiodiversity management. To boost farmer's right, a conceptual hypothesis is proposed where they choose either a new high yielding variety or the existing one and apply conventional breeding approaches to select the seed for next years in their own fields. Although farmers produce seeds traditionally from several years, they have not been guided with scientific discipline to produce sufficient amount of quality seeds. This new concept suggests trained farmers can use breeding approaches to produce quality seed for their own use.
\end{abstract}

Keywords: Farmer's right, food sovereignty, seed production system, conventional breeding

Farmers are regarded as a premier scientist of agriculture because they work as both seed breeders and custodians. They have played huge role to protect indigenous seeds and local germplasms. These germplasms are the basic materials for the initiation of any hybridization program. Farmers have been involved to select seeds for the next season from ancient times with their own experiences. But now the trend of seed selection by farmers are reducing and disappearing because of dominancy of high yielding commercial varieties. Farmers selected local varieties are not able to compete with the new mega varieties and hence they are not interested to 
select their local ones (Kushwaha 2015). The high yielding varieties developed from different companies and institutions are very costly which is beyond the purchasing capacity of a general farmers, and thus there is need to search an option which can help farmers to protect their rights and save economy. Mostly small and middle income generating farmers face huge loss due to the high cost of cultivation, and hence farming become a business of loss or less profit.

Farmers apply huge input materials in their fields so that they can harvest profit. The major inputs include seeds, fertilizers, irrigation, and pesticides. Among them, seed plays a major role. Seed are the foundation of global food system. It is the prime component of the farming system and is the most important input to harvest a good crop (IFPRI). The potential yield of the crop depends on the quality of the seed used for cultivation. Use of quality seeds can alone increase the crop productivity by $15-25 \%$ (Roy 2014). One of the main reasons for low productivity of crops are the unavailability of reliable quality seeds in the local markets. High-quality seed enhances productivity that expresses full potential yield of the variety in favorable environments (Roy 2014). International Seed Federation (2014) data revealed that only 3.5 million metric ton of about 11,947 USD million seed was exported and 3.1 million metric ton of about 11,154 USD million seed was imported worldwide in 2014. If farmers start to produce their own seed, the trend of global seed marketing will decrease at least by 20 to $30 \%$.

Seed systems are of two types: Formal seed system and Informal (Local) seed system. The same general steps (variety choice, variety testing, introduction, seed multiplication, selection, dissemination, and storage) take place in the local system as in the formal sector. In local seed system, farmers treat "seed" as special, or not always necessarily a distinction between "seed" 
and "grain". The steps do not flow in a linear sequence and they are not monitored or controlled by government policies and regulations. Rather, they are guided by local technical knowledge and standards and by local social structures and norms (FAO).

Different approaches of seed production system have been developed and among them, community-based seed production system has recently gained popularity as an alternative to the formal seed sector. This is because community produced seed is readily available and is more affordable by most farmers than certified seed. The community based seed production is a profitable enterprise and is less sensitive to price fluctuations (Katungi et al 2011).

Since ancient times, farmers have been involved in producing seeds by themselves, but the methodologies they apply are traditional, old and experience based. The seeds produced from them are of less quality that cannot be compared with the seeds of private companies. Thus farmers need updated information about seed production techniques. Here, a hypothetical concept of farmer's self-seed production is proposed.

\section{Farmer's Seed Production (FSP) Concept}

"The farmer choose either a new high yielding variety or the existing one and use conventional breeding approaches to select the seeds for next season in their own fields" 


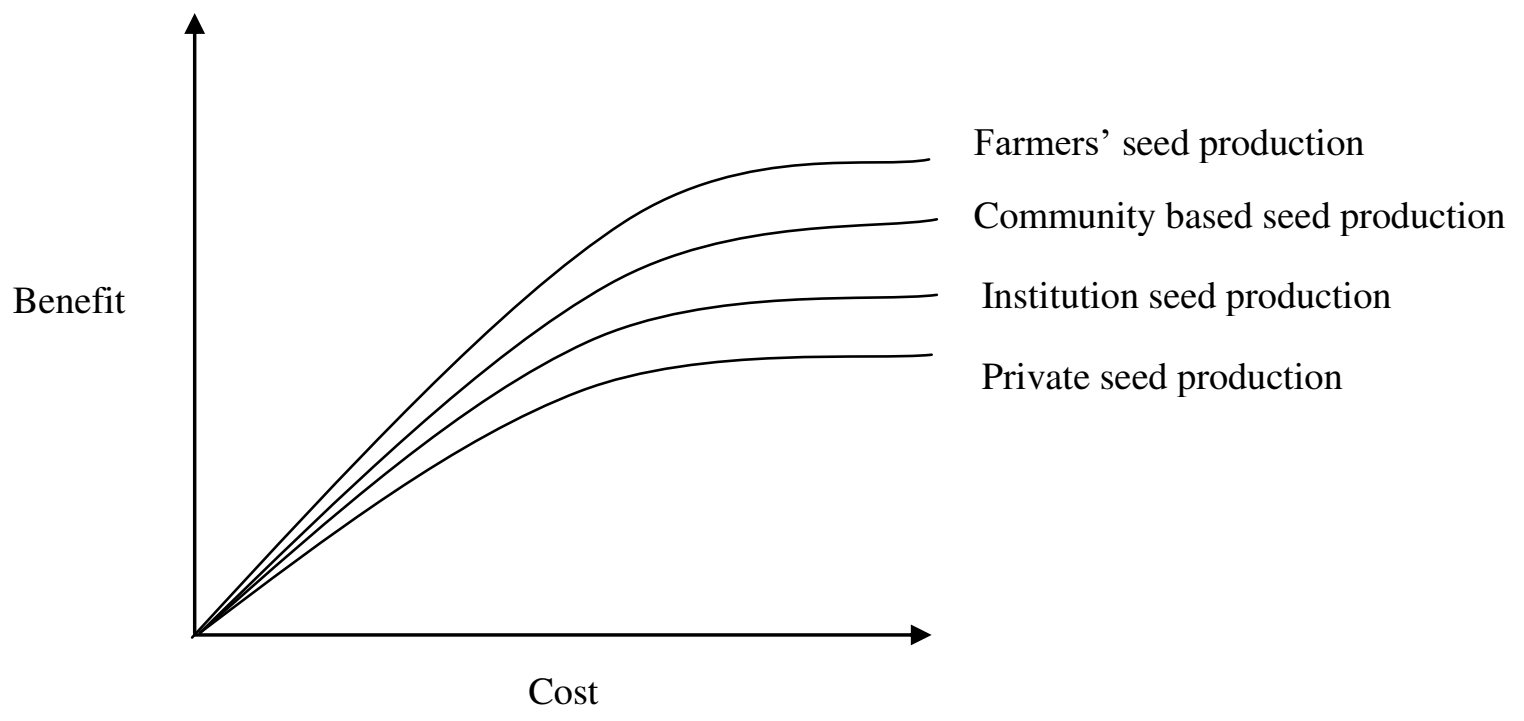

Figure 1 Cost benefit relationships among different seed production systems. Here cost refers to the input materials supplied for seed productions and benefit is the total net profits.

Farmers seed production>community based seed production>Institutional seed production $>$ Private seed production

With the same cost, the benefits obtain from farmer's seed production approach is higher than community, institutional and private seed production approaches. Alternatively with minimum cost, self seed production by farmers gives maximum benefit. Farmer's seed production (FSP) concept suggests that seed production by farmers are better than community and private seed production schemes. This concept is sustainable because farmers can save huge money which they use for purchasing quality seeds. Here, farmers get training on conventional breeding methods of seed selection before they start seed production in their field. For example, farmers select desirable panicles of a high yielding rice variety and store it as next generation seeds. The 
selected panicles should be true to the type, high yielding, and the plant should be free from disease and pests. Similar to rice, farmers can produce seeds of other self-pollinated (SP) crops such as lentil, oat, beans, soybean, tomato, brinjal and wheat. This self seed production approach apply mostly to self pollinated crops only because self-pollinated crops maintains its breeding value and there is no or little chance of heterosis and inbreeding depression. The cross pollinated crop seeds could not be produced by farmers in their fields because it is difficult to maintain pure seeds of cross pollinated crops.

Community seed production

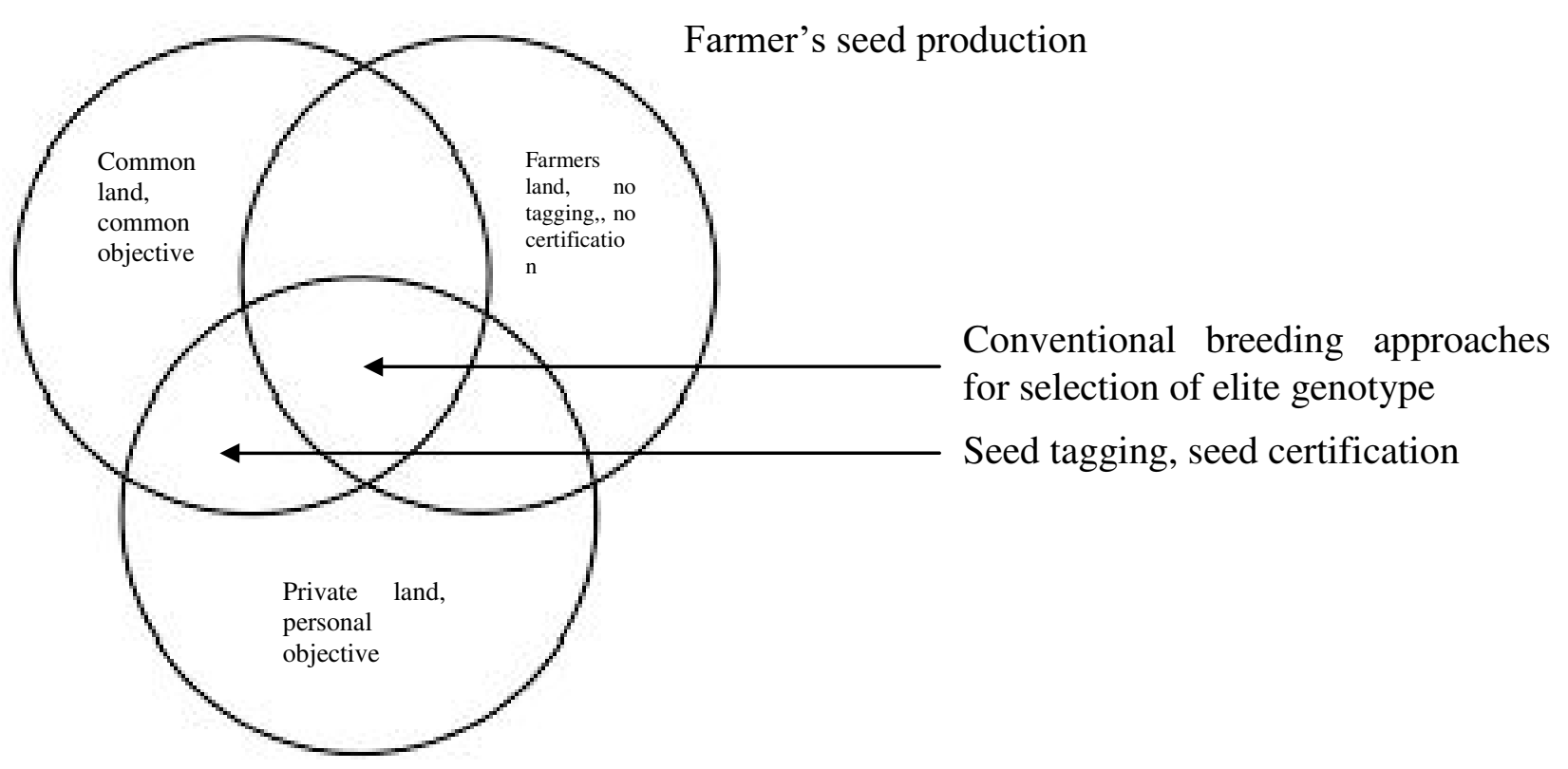

Private seed production

Figure 1. Interrelationships among community based seed production system, private seed production system and farmer's seed production concept through Venn- Diagram

\section{Merits of farmer's seed production}

* This concept applies to produce seeds for any self-pollinated crop variety 
The variety used for seed production might be new/local cultivar or taken from advanced research trial

* Farmers use their improved method of farming for seed production

* Farmer use his own land to produce seed

No extra cost and labors needed

Once seed is received, no need to purchase seed again

Reduction in cost of cultivation

Local and traditional variety can also be saved and promoted

Farming become profitable

* Reduce risk of failure of variety

Fast dissemination of seeds of new variety and promising lines from advanced trial

Restore agricultural biodiversity

No need of seed certification

Seed readily available among the farming community

No government interference

In informal or local seed system, farmers use their own local methods of producing seeds but in FSP, farmer produces the seed using conventional breeding approaches where the quality of seed is better than the local seed system.

The procedure used to produce seed in FSP is similar to other research institutes

Generally farmer use selection and introduction methods of conventional breeding for selecting elite genotypes. In selection he selects a variety with desirable traits whereas introduction introduces a new variety to new environment 


\section{Demerits of farmer's seed production}

Decrease in seed replacement rate

* This concept might not apply for cross-pollinated crops. Since cross pollinated crops have high inbreeding depression and the seed production require high skilled manpower

* This concept does not apply for seed production of self-pollinated hybrid crops

Could promotes traditional varieties.

This concept does not apply in GMO crops.

Farmers produced seed could not be sold in the market since the seed is not certified.

Land may be unavailable for individual farmers.

* Farmer's needs training before self seed production

Knowledge of conventional breeding approaches of seed selection is needed

\section{Difference between Farmer's Seed Production (FSP) and Community Based Seed Production (CBSP) concept}

* Single farmer or their family involves in FSP whereas a group of farmers involve in CBSP

* All managerial decisions based on single farmer in FSP whereas managerial decisions based on a group of farmers CBSP

A farmer can choose their desirable variety to produce seed for next year in FSP but a farmer may or may not choose the desirable variety to produce seed in CBSP

* A common farm in a specific location is conducted by a group of farmers in CBSP whereas individual farmers has their own land in FSP 
A group of farmers involve in selection in CBSP, but only a single farmer and their family involve in FSSP

* The variety may be new or traditional in FSP but variety is always new/commercial in CBSP

* There is a common objective in community based seed production whereas farmer has personal objective in farmer's seed production.

No seed tagging, seed certification needed in FSP but seed tagging, seed certification and variety testing needed in CBSP

\section{Difference between Farmer's Seed Production Concept (FSP) and Participatory Varietal Selection (PVS)}

* Participatory varietal selection needs promising genotypes, but FSP needs either new or traditional high yielding cultivar

* PVS requires a common trial whereas FSP needs individual farmer's land

* A group of farmers involve in variety selection in PVS but only a single farmer and their family involve in seed production in FSP

* A farmer selects seed of a desirable variety in FSP and a common variety selected for varietal release process in PVS

FSP focuses for next year seed production whereas PVS focuses for variety release process

* All managerial decisions based on a single farmer in FSP whereas managerial decisions based on a group of farmers PVS 
The variety may be new or traditional in FSP but variety is always new in CBSP

\section{References}

FAO (2014) Food and Agriculture Organization http://www.fao.org/agriculture/crops/thematicsitemap/theme/compendium/tools-guidelines/what-are-seed-systems/en/ Retrived 8 July 2017

ISF (2014) International Seed Federation www.worldseed.org Retrived $5^{\text {th }}$ September 2017

IFPRI (2017) International Food Policy Research Institute www.ifpri.org Retrived $9^{\text {th }}$ September 2017

Katungi ED, Karajna D, Wozemba T, Mutuoki and JC Rubyogo (2011) A Cost-benefit analysis of farmers based seed production for common bean in Kenya. African Crop Science Journal, Vol. 19, No. 4, pp. $409-415$

Kushwaha UKS, SP Khatiwada, HK Upreti, US Shah, DB Thapa, NB Dhami, SR Gupta, PK Singh, KR Mehta, SK Sah, B Chaudhary, BP Tripathi (2015) Modification of Rice Breeding Technology in $21^{\text {st }}$ Century. International Journal of Bioinformatics and Biomedical Engineering, 1(2):77-84

Roy B (2014) Farmers' participatory quality seed production of field crops-A case study. Journal of Crop and Weed, 10(2):89-93 